\title{
Effects of an Acute Bout of Exercise on Salivary Lactoferrin Responses among Smokers and Non-Smokers
}

\section{Halimatun Saadiah Ahmad $^{1}$, Ayu Suzailiana Muhamad ${ }^{1 *}$}

\author{
${ }^{1}$ Exercise and Sports Science Programme, School of Health Sciences, \\ Universiti Sains Malaysia, 16150 Kota Bharu, Kelantan, MALAYSIA \\ *Corresponding Author
}

DOI: https://doi.org/10.30880/jst.2021.13.01.002

Received 21 October 2020; Accepted 2 March 2021; Available online 18 April 2021

\begin{abstract}
Smoking can weaken immune function as reported in previous studies. However, benefits of exercise in reducing negative effects of smoking on salivary lactoferrin responses is scarce to date. Hence, the purpose of this study is to determine the effects of an acute bout of exercise on salivary lactoferrin responses among smokers and non-smokers. Eighteen sedentary men were recruited; nine smokers (age $=22.4 \pm 1.4$ years; $\mathrm{BMI}=22.1 \pm 1.1 \mathrm{~kg} / \mathrm{m}^{2}$ ) and nine non-smokers (age $=22.1 \pm 0.7$ years old; $\mathrm{BMI}=22.5 \pm 1.9 \mathrm{~kg} / \mathrm{m}^{2}$ ). In this study, participants cycled at an intensity of $60 \%$ maximum heart rate for 60 minutes. Participants were given cool water as much as $3 \mathrm{ml} / \mathrm{kg}$ body weight at minutes 20 and 40 during the exercise session. Participants' body weight and saliva samples were collected at pre and post-exercise. Heart rate and rate of perceived exertion (RPE) were recorded at pre, during and postexercise. Mixed ANOVA was used to measure significant differences between groups and within group. The results showed that saliva flow rate, lactoferrin concentration and lactoferrin secretion rate were not significantly different ( $p>0.05$ ) between smokers and non-smokers groups and also between pre and post-exercise within each group. Heart rate and RPE showed significant increased $(\mathrm{p}<0.05)$ during the exercise session in both groups. As a conclusion, acute bout of exercised does not affect salivary lactoferrin responses among sedentary smokers and non-smokers men.
\end{abstract}

Keywords: Cycling, smokers, saliva, immune function, salivary lactoferrin

\section{Introduction}

Smoking impacts both innate and adaptive immune system by either exacerbating the immune responses or weakening the defense immunity [1]. It was found to reduce the sensitivity of peripheral neutrophils' stimulation by interleukin (IL)-8 which suggesting smoking may interfere the inflammatory process by affecting the release of proinflammatory cytokines [2]. Saliva has defense mechanisms against pathogen microorganisms, in the presence of defense proteins that react in specific (immunoglobulins) or non-specific (lysozyme, peroxidase, cystatins, lactoferrin, hystatins and others) ways, inhibiting microorganisms' growth $[3,4]$. There are two most abundant AMPs produced by epithelial cells and salivary glands, and also localized in granules of neutrophils; lactoferrin and lysozyme [5]. Lactoferrin helps to improve immunity by inhibiting iron uptake by microorganisms, thereby reducing bacterial growth [6]. Meanwhile, lysozyme may enhance protection against gram-positive bacteria [7]. Although smoking is a risk factor for various diseases, people find it is hard to stop smoking. There is a belief that if a person cannot stop smoking, performing a regular exercise might help in reducing the smoking-related risks. It is well known that moderate exercise may enhance immune function [8]. 
Numerous studies have investigated the effects of exercise on immune function among smokers in order to understand how exercise might help smokers to enhance their immune function. For example, previous study found that smokers exhibit elevated monocyte chemo-attractant protein-1 and IL-1 $\beta$ following 40 minutes cycling on a stationary cycle ergometer at $50 \% \mathrm{VO}_{2}$ peak [9]. In addition, a separate study found that preventive exercise impeded histological changes and increased the enzymatic defense system (superoxide dismutase and glutathione peroxidase) by reducing oxidative damage in lipids and proteins [10]. Another study also found positive effects of exercise in inhibiting the effects of smokeinduced chronic obstructive pulmonary disease where, exercise inhibited smoke-induced increases in total leukocytes, neutrophils, lymphocytes, and monocytes in blood, as well as serum levels of IL-1 $\beta$, IL-17, and TNF- $\alpha$, while increased the levels of IL-10 [11].

Nevertheless, to date, to our knowledge, no study has been carried out to investigate the effects of exercise on salivary lactoferrin responses among smokers. Thus, the present study was proposed to be carried out to fill in this gap of knowledge with the objective to determine the effects of exercise on salivary lactoferrin responses among sedentary smokers and nonsmokers.

\section{Methods}

This study employed experimental study design with pre and post-test measurements (Fig. 1). This study was conducted in the Exercise and Sport Science Laboratory of School of Health Sciences, Universiti Sains Malaysia (USM), Kota Bharu, Kelantan. This study has been approved by the Human Research and Ethics Committee of USM (Code: USM/JEPeM/17020119). Participants were recruited among USM students and staff. Sample size was calculated by using PS Software. Based on a study which was carried out by Gillium et al. [12], the power of the study was set at $80 \%$ with $95 \%$ confident interval, the standard deviation $(\sigma)$ observed was 750 (units $/ \mathrm{ml}$ ) of lactoferrin concentration, and difference in population mean $(\delta)$ was set at 1035 (units $/ \mathrm{ml}$ ) of lactoferrin concentration. The calculated sample size was 9 participants per group. Thus, 18 participants were recruited in the present study. They were male with age between 20 to 30 years old, healthy, non-smokers or smokers (10-20 sticks per day with years of smoking of at least 2 years), not physically active (exercise not more than once per week), and answered 'no' to all questions in the Physical Activity Readiness Questionnaire (PAR-Q+) during pre-exercise health screening. Besides, the exclusion criteria include those who are on medication and involved in other exercise programme. After recruitment process, participants' height and weight were measured and their body mass index (BMI) was calculated. Participant's workload at 50\% and $60 \%$ of their maximum heart rate (HRmax) was calculated. Participant's HRmax was calculated by using this formula: 220 - Age (years).

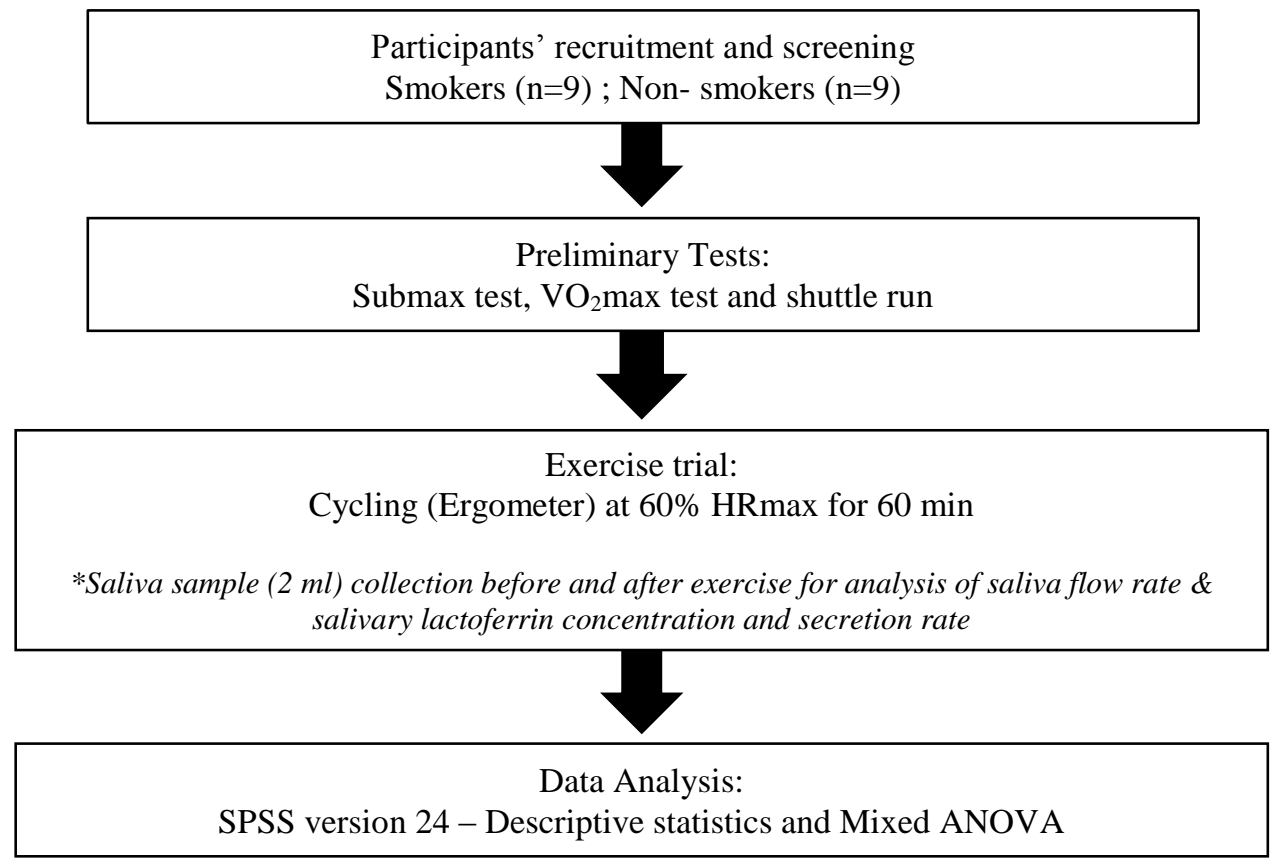

Fig. 1 - Flow chart of the study procedures

Participants came to the laboratory after an overnight fast on the exercise trial day. Saliva sample $(2 \mathrm{ml})$ was collected to determine saliva flow rate and salivary lactoferrin concentration and secretion rate. Saliva sample was obtained by 5 minutes un-stimulated dribbling into a pre-weighed collection tube. During the saliva sample collection, they were asked to sit on chair, lean their head forward and let the saliva passively dribble into the tube (without using tongue and mouth movement). The tube with saliva was then weighed and recorded. 
The exercise trial was begun with 5 min warm up by cycling on an ergometer at $50 \%$ HRmax, followed by cycling on an ergometer at $60 \%$ HRmax for $60 \mathrm{~min}$. During cycling, HR and rate of perceived exertion (RPE) were recorded at every $20 \mathrm{~min}$. In addition, they were given $3 \mathrm{ml} / \mathrm{kg}$ body weight of cool water to avoid dehydration at min 20 and 40 during exercise. Immediately post-exercise, a second saliva sample $(2 \mathrm{ml})$ was collected. Lactoferrin was analysed by using a commercially available reagent kit (Assaypro, USA) via the ELISA method. Following are how the saliva flow rate and salivary lactoferrin secretion rate were calculated in this study:

Saliva flow rate $(\mathrm{ml} / \mathrm{min})=$ Saliva volume $(\mathrm{ml}) /$ Collection time $(\mathrm{min})$

Saliva lactoferrin secretion rate $(\mu \mathrm{g} / \mathrm{min})=$ Saliva flow rate $(\mathrm{ml} / \mathrm{min}) \times$ Saliva lactoferrin concentration $(\mu \mathrm{g} / \mathrm{ml})$

Data gathered were analysed by using Statistical Package for Social Science (SPSS) software, version 24.0 for Windows. The tests used were the descriptive statistics and mixed analysis of variance (ANOVA). The accepted level of significance was set at $\mathrm{p}<0.05$. Results were reported as mean \pm standard deviation (SD).

\section{Results}

\subsection{Physical and Physiological Characteristics}

Mean age, weight, height, and BMI of the participants are shown in the Table 1. Descriptive statistics showed no significant different ( $p>0.05)$ of age, weight, height and BMI values between groups were. Mean of HR and RPE of the participants at pre and post- exercise were also tabulated in the Table 1. Mixed ANOVA revealed significant interaction on HR and RPE where, they were significantly increased over the time (time effect): HR $(F=2.2 ; \mathrm{df}=3 ; \mathrm{p}=0.104)$ and RPE $(\mathrm{F}=0.8 ; \mathrm{df}=3 ; \mathrm{p}=0.458)$. The value of HR and RPE at baseline (pre) and at the end of the exercise (post) were shown in the Table 1.

\subsection{Saliva Flow Rate}

The average of saliva flow rate for smokers and non-smokers groups are shown in the Fig. 2. Mixed ANOVA revealed that there was no significant interaction between time and group on saliva flow rate $(\mathrm{F}=0.08 ; \mathrm{df}=1 ; \mathrm{p}=0.774)$.

Table 1 - Physical and physiological characteristics of the participants in both groups.

\begin{tabular}{|c|c|c|c|c|}
\hline Variables & & $\begin{array}{c}\text { Smokers group } \\
(\mathrm{n}=9)\end{array}$ & $\begin{array}{l}\text { Non-smokers group } \\
\quad(n=9)\end{array}$ & p value \\
\hline Age (years) & & $22.4 \pm 1.4$ & $22.1 \pm 0.7$ & 0.241 \\
\hline Weight (kg) & & $61.7 \pm 4.3$ & $65.0 \pm 5.7$ & 0.114 \\
\hline Height $(\mathrm{cm})$ & & $166.7 \pm 5.6$ & $169.9 \pm 6.2$ & 0.188 \\
\hline $\mathrm{BMI}\left(\mathrm{kg} / \mathrm{m}^{2}\right)$ & & $22.1 \pm 1.1$ & $22.5 \pm 1.9$ & 0.405 \\
\hline \multirow{2}{*}{ HR (beats/min) } & Pre & $80.4 \pm 4.2$ & $82.1 \pm 5.1$ & \multirow{2}{*}{$\begin{array}{c}\mathrm{F}=2.2 ; \mathrm{df}=3 \\
\mathrm{p}=0.104\end{array}$} \\
\hline & Post & $145.8 \pm 6.8$ & $146.4 \pm 7.5$ & \\
\hline \multirow{2}{*}{ RPE (Borg's unit) } & Pre & $6.0 \pm 0.0$ & $6.0 \pm 0.0$ & \multirow{2}{*}{$\begin{array}{c}\mathrm{F}=0.8 ; \mathrm{df}=3 \\
\mathrm{p}=0.458\end{array}$} \\
\hline & Post & $13.5 \pm 1.5$ & $14.0 \pm 0.5$ & \\
\hline
\end{tabular}

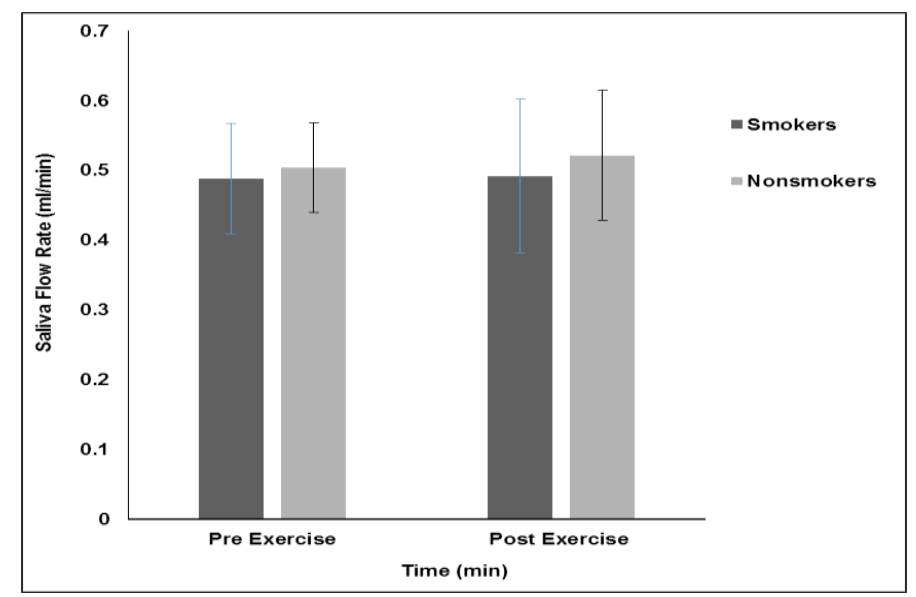

Fig. 2 - Saliva flow rate $(\mathrm{ml} / \mathrm{min})$ at pre and post-exercise for both groups

(No significant difference between and within group). 


\subsection{Salivary Lactoferrin Concentration}

The average of salivary lactoferrin concentration for both groups are shown in the Fig. 3. Mixed ANOVA revealed that there was no significant interaction between time and group on salivary lactoferrin concentration $(\mathrm{F}=1.3 ; \mathrm{df}=1 ; \mathrm{p}$ $=0.270)$.

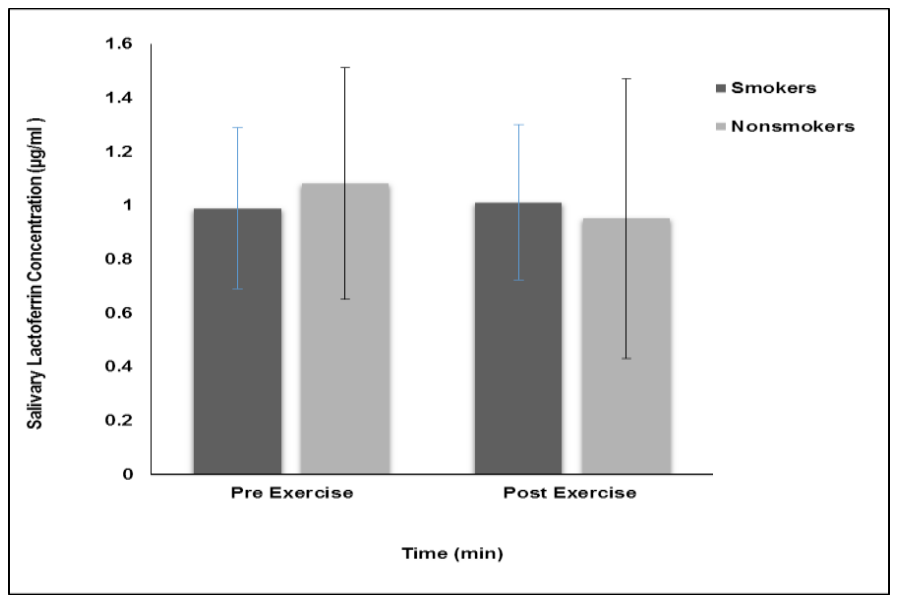

Fig. 3 - Salivary lactoferrin concentration $(\mu \mathrm{g} / \mathrm{ml})$ at pre and post-exercise for both groups (No significant difference between and within group)

\subsection{Salivary Lactoferrin Secretion Rate}

The average of salivary lactoferrin secretion rate for smokers and non-smokers groups are shown in the Fig. 4. Mixed ANOVA revealed that there was no significant interaction between time and group on salivary lactoferrin secretion rate $(\mathrm{F}=0.28 ; \mathrm{df}=1 ; \mathrm{p}=0.60)$.

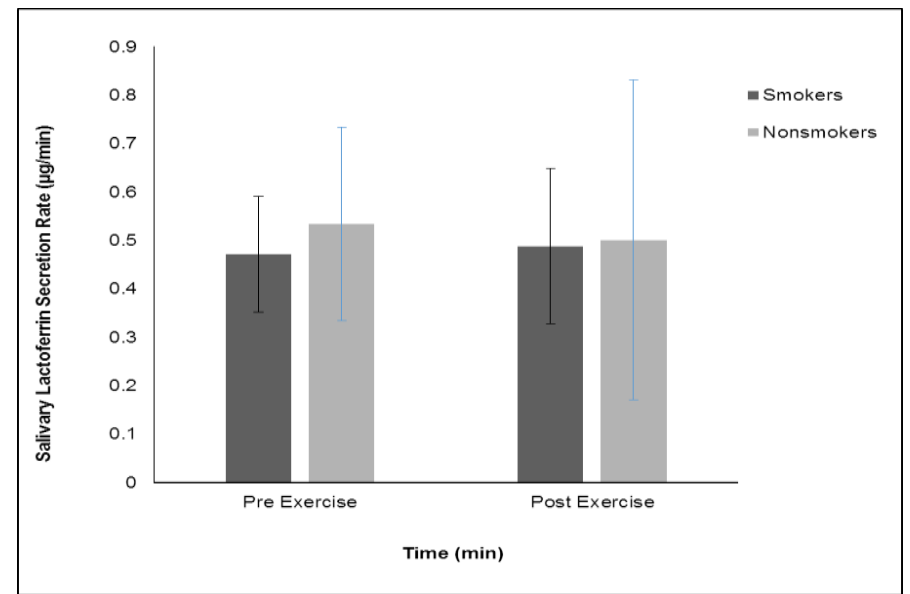

Fig. 4 - Salivary lactoferrin secretion rate $(\mu \mathrm{g} / \mathrm{min})$ at pre and post-exercise for both groups (No significant difference between and within group)

\section{Discussion}

\subsection{Saliva Flow Rate}

In the present study, there was no significant difference on saliva flow rate between groups (group effect) and within each group (time effect) (Fig. 2), indicating that there is no effect of acute bout of moderate exercise on saliva flow rate. Several other studies also reported similar findings whereby saliva flow rate was not affected by exercise [10,13]. Nevertheless, there were also studies reporting significant effects of exercise on saliva flow rate; reduced following prolonged exercise [14]. This discrepancy may be attributed to nutritional status of the individual and the exercise protocol employed.

There are some factors to be considered when measuring saliva; whether or not saliva flow rate has been stimulated, since this has been shown to change the composition of the saliva as well as the volume [15]. Stimulation of saliva glands by sympathetic nervous activity reduces saliva flow rate via vasoconstriction of the blood vessels supplying the salivary glands. While sympathetic stimulation is known to exert some control over glandular blood flow, it is important to note that this is not part of the reflex salivary response to stimuli such as anxiety, chewing, taste and sight of food [16]. 
Under reflex conditions, it has been shown that vasoconstriction is not responsible for altered saliva volume because only sympathetic nerve fibres and not vasoactive nerve fibres are stimulated [16]. Thus, decrease in flow rate associated with exercise is more likely related to a removal of parasympathetic vasodilatory influences rather than sympatheticallymediated vasoconstriction, particularly since sensations of 'dry mouth' associated with psychological stress are related to parasympathetic withdrawal rather than sympathetic activation [17].

\subsection{Salivary Lactoferrin Concentration and Secretion Rate}

In the present study, it was found that lactoferrin concentration and secretion rate (Fig. 3 and 4) was not significantly different between and within groups. In agreement with our study findings, several other studies also reported similar findings $[18,19,20]$. Nevertheless, these previous studies were conducted among athletes and non-smoking population. As mentioned before, to our knowledge, this is the first study carried out to investigate the effects of exercise on salivary lactoferrin among smokers.

Concentration of lactoferrin has been reported increasing immediately after $30 \mathrm{~min}$ of intense running and was associated with elevated serum antibacterial activity [21]. Fielding et al. [22] also stated that levels of lactoferrin also increased following a 2-hour submaximal cycle followed by a bout of eccentric resistance exercise. Similarly, a previous study by Gillum et al. [12] found that exercise increased the concentration of salivary AMPs including lactoferrin concentration from pre to post-exercise with running at $75 \% \mathrm{VO}_{2} \max$ for 45 minutes. However, a separate study found that salivary lactoferrin concentrations decreased during a training season in elite rowers [23]. Similarly, another study reported that salivary lactoferrin decreased due to an intense training session [24]. These inconsistent findings were as a result of different study population and exercise protocol employed.

It has been suggested that an increase in the concentration of salivary AMPs after exercise, might confer improved immunity to infection [18]. Hydration during exercise may affect the ability to maintain adequate salivary AMPs secretion rates despite lower concentrations [25]. Therefore, maintaining hydration may be an important factor in maintaining mucosal immune integrity. Since both smokers and non-smokers participants in the present study were hydrated during exercise, this might explain the non-significant difference found on salivary lactoferrin responses between and within groups.

\section{Conclusion}

In conclusion, the present study found that an acute bout of moderate intensity exercise does not induce beneficial effects on mucosal immunity among smokers and non-smokers population. This might be attributed to the exercise mode employed in the present study. Thus, the following recommendations are advised for future studies; first by involving chronic effects of exercise rather than acute bout of exercise. Chronic exercise for at least 6 weeks might produce significant benefits of exercise among smokers. Secondly, by including measurements of other salivary antimicrobial proteins e.g. lysozyme and Ig A.

\section{Acknowledgement}

We would like to thank all the participants and staff of Exercise and Sports Science Laboratory, USM for their commitment and cooperation given in this study.

\section{References}

[1] Qiu, F., Liang, C. L., Liu, H., Zeng, Y. Q., Hou, S., Huang, S., Lai, X., \& Dai, Z. (2017). "Impacts of cigarette smoking on immune responsiveness: Up and down or upside down?" in Oncotarget, Vol. 8. No. 1 pp. 268-284

[2] Fredriksson, M., Bergstrom, K., \& Asman, B. (2002). "Effect of cigarette smoking: A pilot study" in Journal of Clinical Periodontology, Vol. 29. No. 2 pp. 123-128.

[3] Lawrence, H. P. (2002). "Salivary markers of systemic disease: Non-invasive diagnosis of disease and monitoring of general health" in Journal of the Canadian Dental Association, Vol. 68. No. 3 pp. 170-174

[4] van Nieuw Amerongen A., Bolscher, J. G., \& Veerman, E. C. (2004). "Salivary proteins: Protective and diagnostic value in cariology?" in Caries Research, Vol. 38. No. 3 pp. 247-253

[5] Dubin, R. F., Robinson, S. K., \& Widdicombe, J. H. (2004). "Secretion of lactoferrin and lysozyme by cultures of human airway epithelium" in American Journal of Physiology-Lung Cellular and Molecular Physiology, Vol. 286. No. 4 pp. L750-L755.

[6] Weinberg, E. D. (1992). "Iron depletion: A defense against intracellular infection and neoplasia" in Life Sciences, Vol. 50. No. 18 pp. 1289-1297

[7] Leitch, E. C., \& Willcox, M. D. (1998). "Synergic antistaphylococcal properties of lactoferrin and lysozyme" in Journal of Medical Microbiology, Vol. 47. No. 9 pp. 837-842

[8] Nieman, D. C. (1994). "Exercise, infection, and immunity" in International Journal of Sports Medicine, Vol. 15. No. Suppl 3 pp. S131-S141 
[9] Kastelein, T. E., Duffield, R., \& Marino, F. E. (2015). “Acute Immune-Inflammatory Responses to a Single Bout of Aerobic Exercise in Smokers; The Effect of Smoking History and Status" in Frontiers in immunology, Vol. 6. pp. 634

[10] Ibrahim, N. S., Ooi, F. K., Chen, C. K., \& Muhamad, A. S. (2018). "Effects of probiotics supplementation and circuit training on immune responses among sedentary young males" in Journal of Sports Medicine and Physical Fitness, Vol. 58. No. 7-8 pp. 1102-1109

[11] Rodrigues Brandao-Rangel, M. A., Bachi, A., Oliveira-Junior, M. C., Abbasi, A., Silva-Renno, A., Aparecida de Brito, A., Ligeiro de Oliveira, A. P., Choqueta Toledo-Arruda, A., Belvisi, M. G., \& Paula Vieira, R. (2017). "Exercise Inhibits the Effects of Smoke-Induced COPD Involving Modulation of STAT3" in Oxidative medicine and cellular longevity, Vol. 2017, No. 6572714

[12] Gillum, T. L., Kuennen, M. R., McKenna, Z., Castillo, M. N., Jordan-Patterson, A. T., \& Bohnert, C. (2017). "Exercise increases lactoferrin, but decreases lysozyme in salivary granulocytes" in European Journal of Applied Physiology, Vol. 117. No. 5 pp. 1047-1051

[13] Allgrove, J. E., Gomes, E., Hough, J., \& Gleeson, M. (2008). "Effects of exercise intensity on salivary antimicrobial proteins and markers of stress in active men" in Journal of Sports Sciences, Vol. 26. No. 6 pp. 653-661

[14] Leicht, C.A., Goosey-Tolfrey, V.L. \& Bishop, N.C. (2018). "Exercise intensity and its impact on relationships between salivary immunoglobulin A, saliva flow rate and plasma cortisol concentration" in European Journal of Applied Physiology, Vol. 118. No. 6 pp. 1179-1187

[15] Gleeson, M., McDonald, W. A., Cripps, A. W., Pyne, D. B., Clancy, R. L., \& Fricker, P. A. (1995). "The effect on immunity of long-term intensive training in elite swimmers" in Clinical and Experimental Immunology, Vol. 102. No. 1 pp. $210-216$

[16] Proctor, G. B., \& Carpenter, G. H. (2007). "Regulation of salivary gland function by autonomic nerves" in Autonomic Neuroscience, Vol. 133. No. 1 pp. 3-18

[17] Allgrove, J. E., Oliveira, M., \& Gleeson, M. (2014). "Stimulating whole saliva affects the response of antimicrobial proteins to exercise" in Scandinavian Journal of Medicine and Science in Sports, Vol. 24. No. 4 pp. 649-655

[18] West, N. P., Pyne, D. B., Kyd, J. M., Renshaw, G. M., Fricker, P. A., \& Cripps, A. W. (2010). "The effect of exercise on innate mucosal immunity" in British Journal of Sports Medicine, Vol. 44. No. 4 pp. 227-231

[19] Svendsen, I. S., Hem, E., \& Gleeson, M. (2016). "Effect of acute exercise and hypoxia on markers of systemic and mucosal immunity" in European Journal of Applied Physiology, Vol. 116. No. 6 pp. 1219-1229

[20] McKenna, Z., Berkemeier, Q., Gorini, F., Kuennen, M., Naylor, A., Kleint, A. \& Gillum, T. (2020). "Effects of exercise in hot and humid conditions and bovine colostrum on salivary immune markers" in Journal of Thermal Biology, Vol. 93. No. 102717

[21] Inoue, H., Sakai, M., Kaida, Y., \& Kaibara, K. (2004). "Blood lactoferrin release induced by running exercise in normal volunteers: Antibacterial activity" in Clinical Chimica Acta, Vol. 341. No. 1-2 pp. 165-172

[22] Fielding, R. A., Violan, M. A., Svetkey, L., Abad, L. W., Manfredi, T. J., Cosmas, A., \& Bean, J. (2000). "Effects of prior exercise on eccentric exercise-induced neutrophilia and enzyme release" in Medicine \& Science in Sports \& Exercise, Vol. 32. No. 2 pp. 359-364

[23] West, N. P., Pyne, D. B., Renshaw, G., \& Cripps, A. W. (2006). “Antimicrobial peptides and proteins, exercise and innate mucosal immunity” in FEMS Immunology and Medical Microbiology, Vol. 48. No. 3 pp. 293-304

[24] Cox, G., Pyne, D. B., Kyd, J. M., McDonald, W. A., Fricker, P. A., \& Cripps, A. W. (1999). "Salivary lactoferrin as a marker of immunocompetence in elite swimmers" in International Journal of Sports Medicine, Vol. 21. No. S1 pp. S83-S84

[25] Fortes, M. B., Diment, B. C., Di Felice, U., \& Walsh, N. P. (2012). "Dehydration decreases saliva antimicrobial proteins important for mucosal immunity” in Applied Physiology, Nutrition, and Metabolism, Vol. 37 . No. 5 pp. 850859 